\title{
Synthesis and characterization of $\mathrm{NiFe}_{2} \mathrm{O}_{4}$ nanopowders via spray pyrolysis
}

\author{
Dae Soo JUNG, Hee Chan JANG, Man-Jong LEE, ${ }^{*}$ Kyeong Youl JUNG** and Yun Chan KANG ${ }^{\dagger}$ \\ Department of Chemical Engineering, Konkuk University, 1 Hwayang-dong, Gwangjin-gu, Seoul 143-701, Korea \\ *Department of Advanced Technology Fusion, Konkuk University, 1 Hwayang-dong, Gwangjin-gu, Seoul 143-701, Korea \\ ** Department of Chemical Engineering, Kongju National University, 182 Shinkwan-dong, Kongju, Chungnam 314-701, Korea
}

\begin{abstract}
$\mathrm{NiFe}_{2} \mathrm{O}_{4}$ powders with large-sized, hollow, and thin wall structures were directly prepared by spray pyrolysis from a spray solution containing citric acid. These as-prepared powders converted into nanosized $\mathrm{NiFe}_{2} \mathrm{O}_{4}$ powders after post-treatment at high temperatures between 600 and $1000^{\circ} \mathrm{C}$. Phase-pure $\mathrm{NiFe}_{2} \mathrm{O}_{4}$ powders were obtained at post-treatment temperatures between 700 and $1000^{\circ} \mathrm{C}$. When the post-treatment temperatures were increased from 700 to $1000^{\circ} \mathrm{C}$, the BET surface areas of the $\mathrm{NiFe}_{2} \mathrm{O}_{4}$ powders decreased from 23.4 to $11.8 \mathrm{~m}^{2} / \mathrm{g}$ and their mean sizes increased from 47.8 to $94.7 \mathrm{~nm}$, respectively. The saturation magnetizations of the powders changed from 32 to $44 \mathrm{emu} / \mathrm{g}$ according to changes in the post-treatment temperatures. The coercivities of the powders post-treated at temperatures of 700 and $800^{\circ} \mathrm{C}$ were 118 and $130 \mathrm{Oe}$, respectively. (๑2009 The Ceramic Society of Japan. All rights reserved.
\end{abstract}

\section{Introduction}

Due to the extremely small sizes or large specific surface areas of nanomagnetic powders, they have unusual physical and chemical properties that are significantly different from those of conventional bulk materials. ${ }^{1)-3)}$ Nanomagnetic powder materials have been employed in many applications such as high-density magnetic recording and magnetic fluids for the storage and/or retrieval of information, magnetic resonance imaging (MRI) enhancement, catalysis, magnetically guided drug delivery, and sensors. ${ }^{4)-6)}$ Among various nanomagnetic powders, $\mathrm{NiFe}_{2} \mathrm{O}_{4}$ powder is one of the most important. In the past, various methods have been developed for preparing $\mathrm{NiFe}_{2} \mathrm{O}_{4}$ powders with desired properties, such as solid-state reactions, citrate precursor technique, coprecipitation, mechanical alloying, sol-gel method, shock wave technique, reverse micelle method, and a hydrothermal process. ${ }^{7)-13)}$

Spray pyrolysis, an aerosol process, has been successfully applied to the preparation of ceramic powders, because it is a simple, inexpensive, and continuous process. It is also used to prepare ferrite materials. For example, González-Carreño et al. prepared barium ferrite nanopowders by spray pyrolysis. ${ }^{14}$ Nanosized powders were directly prepared by aerosol pyrolysis from the citrate aqueous solution with low metal concentration of $0.02 \mathrm{M}$. Further, $\mathrm{Li}$ et al. investigated the effects of various combinations of chlorides and nitrates of manganese and iron on the morphology, phase, surface area, and magnetic properties of $\mathrm{MnFe}_{2} \mathrm{O}_{4}$ powders prepared by spray pyrolysis. ${ }^{15)}$ In addition, $\mathrm{Yu}$ and Gadalla prepared $\mathrm{NiFe}_{2} \mathrm{O}_{4}$ powders by spray pyrolysis and investigated the effects of operating parameters on the quality of the aerosol product. ${ }^{16)}$

In this study, $\mathrm{NiFe}_{2} \mathrm{O}_{4}$ powders with large-sized, hollow, and thin wall structures were directly prepared by spray pyrolysis from a spray solution containing an organic additive. After being

Corresponding author: Y. C. Kang; E-mail: yckang@konkuk.ac.kr post-treated at high temperatures, these powders converted into nanosized $\mathrm{NiFe}_{2} \mathrm{O}_{4}$ powders. The mean sizes of the $\mathrm{NiFe}_{2} \mathrm{O}_{4}$ powders were controlled by changing the post-treatment temperatures. Effects of the post-treatment temperatures on the mean sizes, BET surface areas, saturation magnetizations, and coercivities of the $\mathrm{NiFe}_{2} \mathrm{O}_{4}$ powders were investigated.

\section{Experiments}

The schematic diagram of spray pyrolysis system used in this work is given elsewhere. ${ }^{17)}$ The system consists of droplet generator, quartz reactor, and powder collector. A $1.7 \mathrm{MHz}$ ultrasonic spray generator having six vibrators was used to generate large amount of droplets, which are carried into the high-temperature tubular reactor by air as the carrier gas. The length and diameter of the quartz reactor are 1200 and $50 \mathrm{~mm}$, respectively. Iron chloride and nickel chloride as starting materials were used. The overall concentration of $\mathrm{Ni}$ and $\mathrm{Fe}$ components was fixed at $0.2 \mathrm{M}$. The concentration of citric acid used as organic additive was $0.4 \mathrm{M}$. The flow rate of air used as carrier gas was $45 \mathrm{~L} / \mathrm{min}$. The as-prepared powders obtained by spray pyrolysis at $900^{\circ} \mathrm{C}$ were post-treated in a box furnace at a temperature between 600 and $1000^{\circ} \mathrm{C}$ for $2 \mathrm{~h}$ in air atmosphere to change the crystallinity and morphology.

The crystal structures of the as-prepared and post-treated $\mathrm{NiFe}_{2} \mathrm{O}_{4}$ powders were investigated by X-ray diffractometry (XRD; RIGAKU Co., DMAX-33). The morphological characteristics of the powders were investigated by scanning electron microscopy (SEM; JEOL Ltd., JSM 6060). Measurement of the thermal properties of the precursor powders was performed on a thermo-analyzer (TG-DSC; Netzsch, STA409C, Germany) in the temperature range from 40 to $900^{\circ} \mathrm{C}\left(10^{\circ} \mathrm{C} / \mathrm{min}\right)$. Surface areas of the powders were measured by the Brunauer-EmmettTeller (BET) method using $\mathrm{N}_{2}$ as the adsorbate gas. The powder size was estimated from specific surface area assuming spherical shape. A vibrating sample magnetometer (VSM; 7300 Lakeshore, USA) was used to measure the saturation magnetization 
of the nickel ferrite powders as well as the coercive force.

\section{Results and discussion}

XRD patterns of as-prepared powders obtained by spray pyrolysis from spray solutions with and without citric acid are shown in Fig. 1. Addition of citric acid to the spray solution changed the crystal structures of the as-prepared powders obtained by spray pyrolysis. The powders prepared from the spray solution with citric acid were poorly crystallized and the main phase was spinel $\mathrm{NiFe}_{2} \mathrm{O}_{4}$. On the other hand, the powders prepared from the spray solution without citric acid were mainly composed of nickel chloride hydrate and iron oxide phases. The differences between the phase compositions may be attributed to the formation of the citric acid chelates of $\mathrm{Ni}$ and $\mathrm{Fe}$, which may change dried droplets to viscous melts. Evolution of gases in the decomposition of the chelates may inflate the droplets making the particles hollow. ${ }^{18)}$ The as-prepared powders by spray pyrolysis from the spray solution with citric acid had broad XRD peaks, which may be attributed to the short residence time $(0.45 \mathrm{~s})$ of the powders inside the reactor.

Figure 2 shows TG/DSC curves of the as-prepared powders obtained by spray pyrolysis from the spray solutions with and without citric acid. The TG curve of the powders prepared from

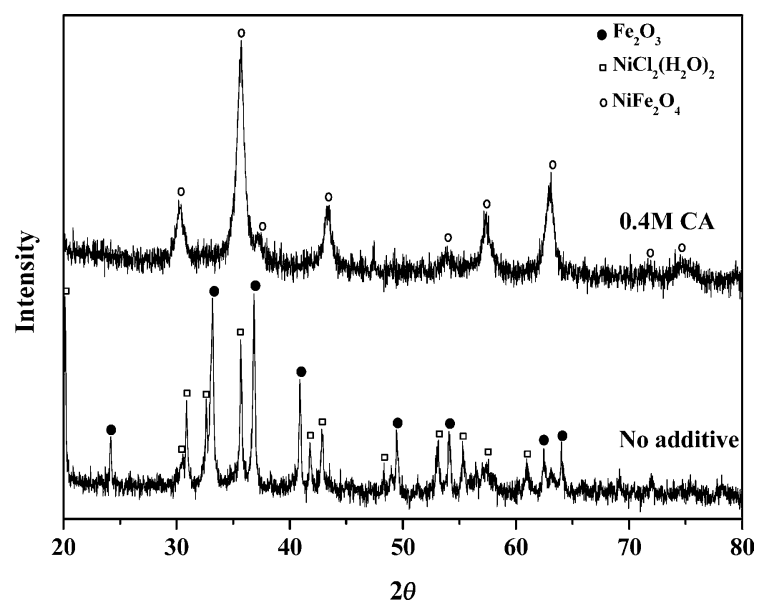

Fig. 1. XRD patterns of as-prepared powders obtained from the spray solutions with and without citric acid

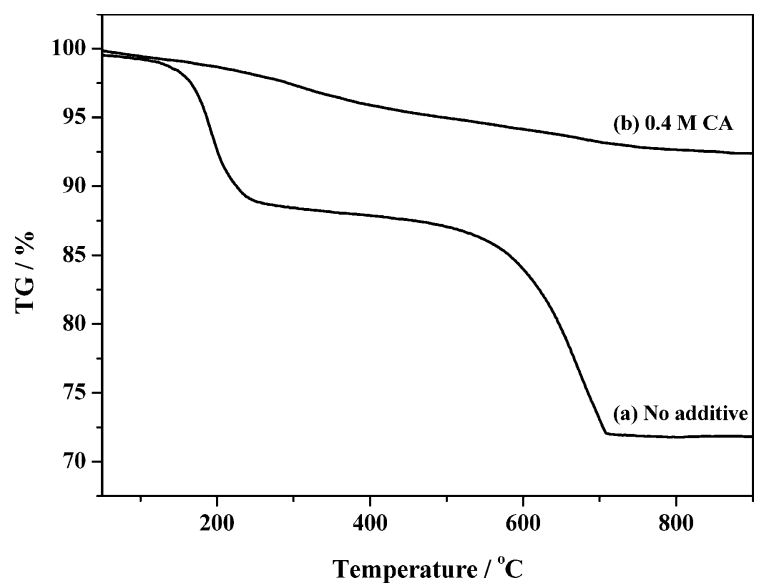

Fig. 2. TG/DSC curves of as-prepared powders obtained from the spray solutions with and without citric acid: (a) No additive, (b) $0.4 \mathrm{M}$ CA.

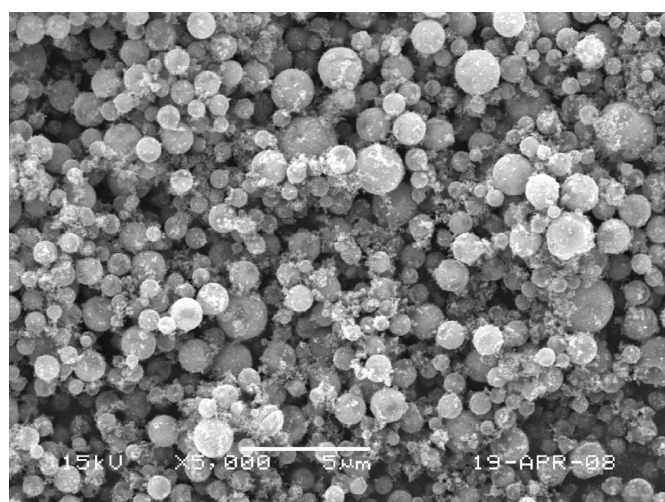

(a) No additive

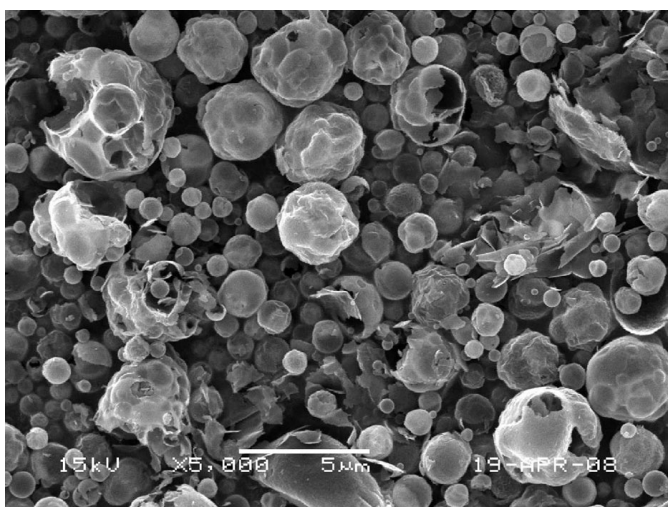

(b) $0.4 \mathrm{M} \mathrm{CA}$

Fig. 3. SEM images of as-prepared powders obtained from the spray solutions with and without citric acid

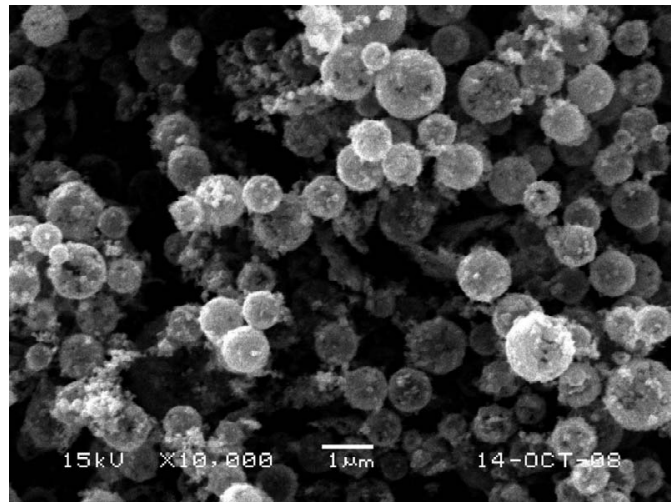

(a) $600^{\circ} \mathrm{C}$

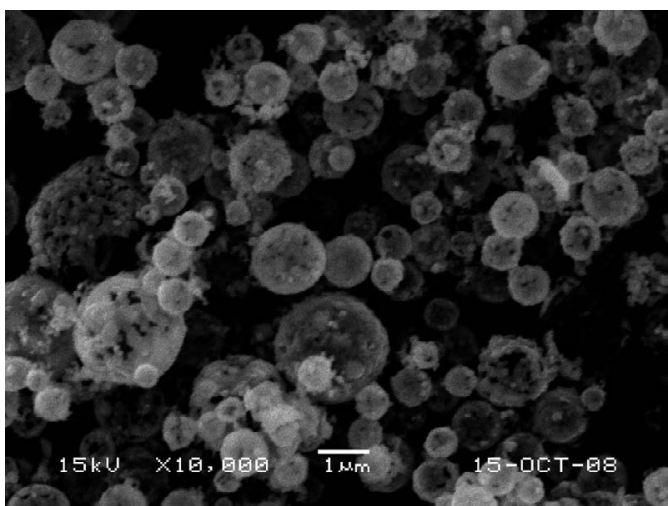

(b) $1000^{\circ} \mathrm{C}$

Fig. 4. SEM images of post-treated $\mathrm{NiFe}_{2} \mathrm{O}_{4}$ powders obtained from the spray solution without citric acid. 
the spray solution without citric acid shows two weight losses at temperatures below $800^{\circ} \mathrm{C}$. The first pronounced weight loss region below $200^{\circ} \mathrm{C}$ is related to the decomposition of the $\mathrm{Fe}$ precursor. The second weight loss region from 450 to $700^{\circ} \mathrm{C}$ is related to the decomposition of the Ni precursor. Because of the short residence time of the powders, complete decomposition of the reactant precursors did not occur in the spray pyrolysis process. On the other hand, in the TG curve of the powders prepared from the spray solution with citric acid, rapid weight loss was not observed. A small weight loss of the powders occurred below $800^{\circ} \mathrm{C}$ due to the burning out of the residual carbon contaminant. The total weight losses of the powders prepared from the spray solutions with and without citric acid were 7.5 and $28.1 \%$, respectively.
Figure 3 shows the SEM images of the as-prepared powders obtained by spray pyrolysis from the spray solutions with and without citric acid. The powders prepared from the spray solution without citric acid had bimodal size distributions with nanometer and micrometer sizes. Nickel chloride used as the source material of the $\mathrm{Ni}$ component had high volatility at a temperature of $900^{\circ} \mathrm{C}$. Therefore, some of the nickel chloride precursor may be evaporated inside the reactor before being decomposed into $\mathrm{NiO}$. The evaporated vapors of the nickel chloride precursor formed nanosized powders by the chemical vapor deposition (CVD) process. Powders with micrometer sizes had spherical shapes. However, those prepared from the spray solution with citric acid had sizes of the order of several micrometers, and their structures were hollow. Evolution of gas by the decom-

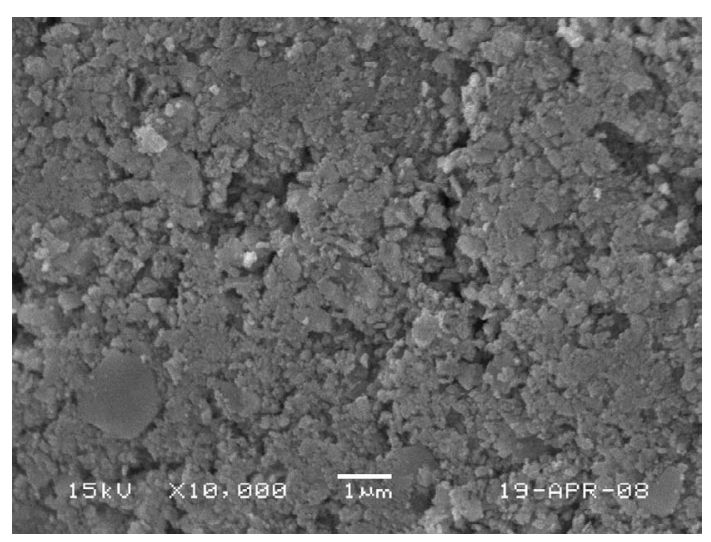

(a) $600^{\circ} \mathrm{C}$

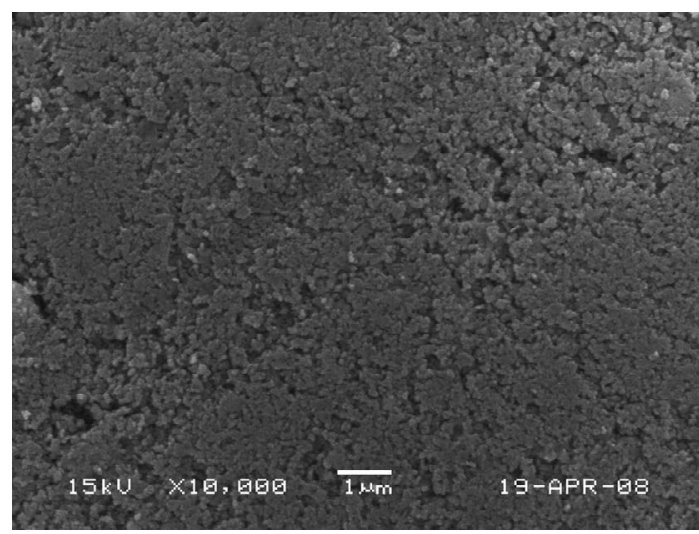

(c) $800^{\circ} \mathrm{C}$

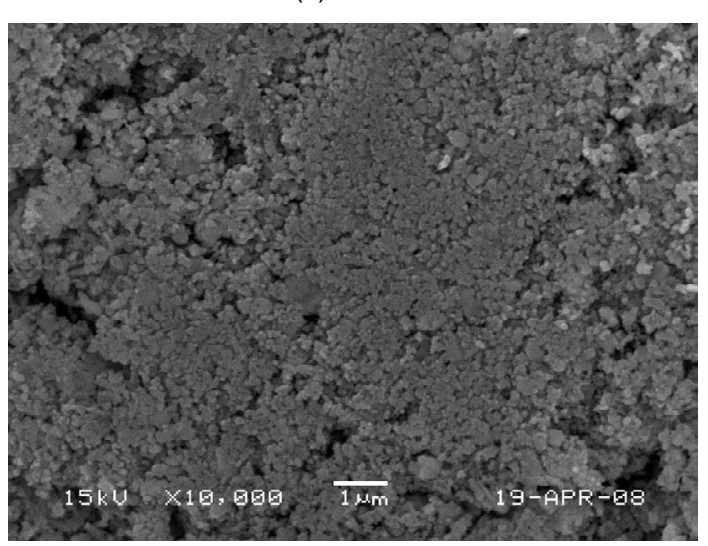

(e) $1000^{\circ} \mathrm{C}$

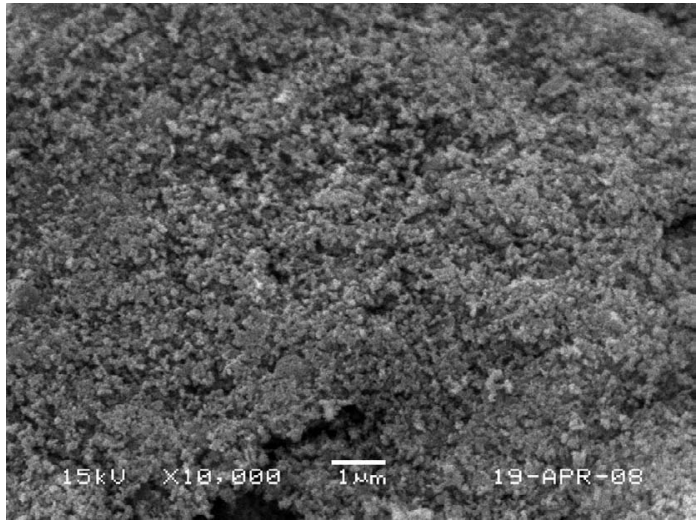

(b) $700^{\circ} \mathrm{C}$

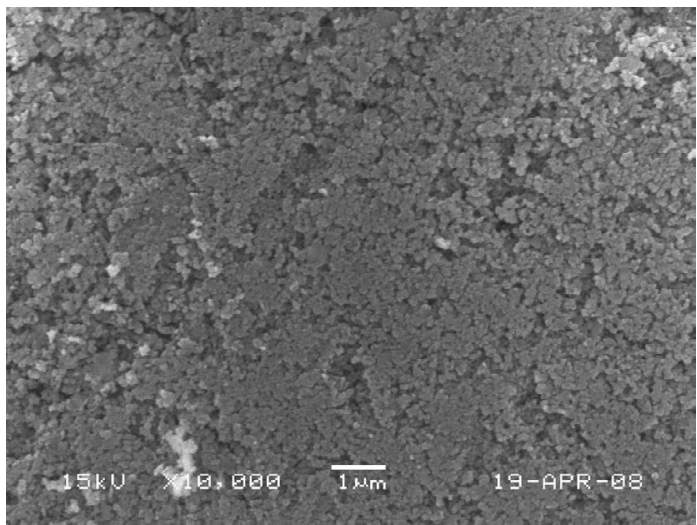

(d) $900^{\circ} \mathrm{C}$

Fig. 5. SEM images of post-treated $\mathrm{NiFe}_{2} \mathrm{O}_{4}$ powders obtained from the spray solution with citric acid. 


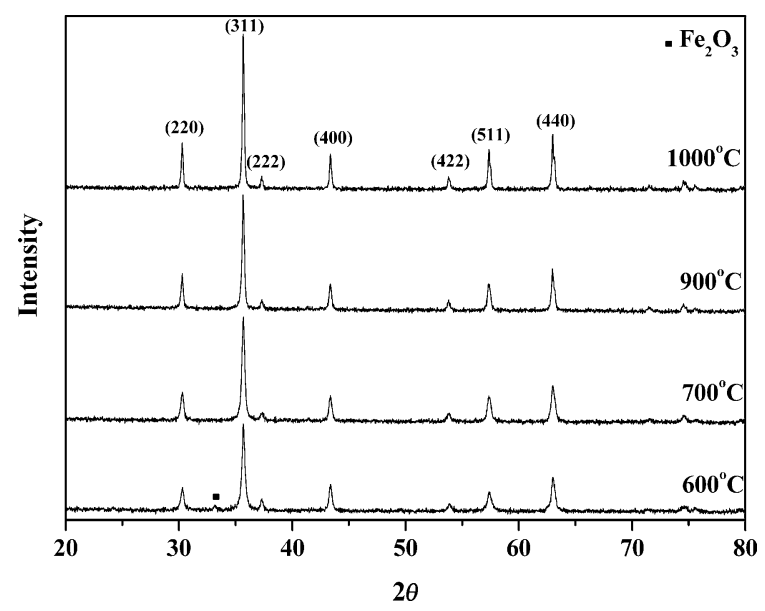

Fig. 6. XRD patterns of $\mathrm{NiFe}_{2} \mathrm{O}_{4}$ powders post-treated at various temperatures.

Table 1. Characteristics of the $\mathrm{NiFe}_{2} \mathrm{O}_{4}$ Powders Post-treated at Various Temperatures

\begin{tabular}{|c|c|c|c|c|}
\hline $\begin{array}{l}\text { Post-treatment } \\
\text { temperature }\left({ }^{\circ} \mathrm{C}\right)\end{array}$ & $\begin{array}{l}\text { Surface } \\
\text { area } \\
\left(\mathrm{m}^{2} / \mathrm{g}\right)\end{array}$ & $\begin{array}{c}\text { Mean } \\
\text { powder size } \\
(\mathrm{nm})\end{array}$ & $\begin{array}{c}\text { Saturation } \\
\text { magnetization } \\
\left(M_{\mathrm{s}}\right)(\mathrm{emu} / \mathrm{g})\end{array}$ & $\begin{array}{l}\text { Coercivity } \\
\left(H_{\mathrm{c}}\right)(\text { Oersted })\end{array}$ \\
\hline 600 & 14 & 79.8 & 32 & 279 \\
\hline 700 & 23.4 & 47.8 & 40 & 118 \\
\hline 800 & 17.1 & 65.3 & 40.5 & 130 \\
\hline 900 & 16 & 69.9 & 42.5 & 133 \\
\hline 1000 & 11.8 & 94.7 & 44.1 & 110 \\
\hline
\end{tabular}

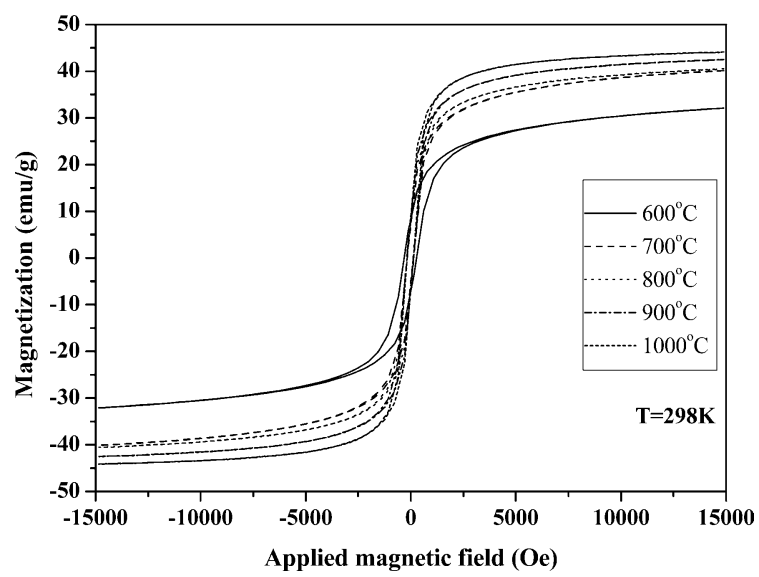

Fig. 7. Hysteresis curves of $\mathrm{NiFe}_{2} \mathrm{O}_{4}$ powders post-treated at various temperatures.

position of citric acid added to the spray solution resulted in powders with hollow structures. The problem of evaporation of nickel chloride was solved by the addition of citric acid to the spray solution by forming the chelates of $\mathrm{Fe}$ and $\mathrm{Ni}$ componensts.

Figure 4 shows $\mathrm{SEM}$ images of post-treated $\mathrm{NiFe}_{2} \mathrm{O}_{4}$ powders obtained from the spray solution without citric acid. The asprepared powders obtained by spray pyrolysis from the spray solution without citric acid were post-treated at temperatures of
600 and $1000^{\circ} \mathrm{C}$. The post-treated $\mathrm{NiFe}_{2} \mathrm{O}_{4}$ powders had hollow and aggregated structure of the nanometer size primary powders.

Micron sized $\mathrm{NiFe}_{2} \mathrm{O}_{4}$ powders turned to the nano-sized powders by weak press. Figure 5 shows SEM images of the pressed $\mathrm{NiFe}_{2} \mathrm{O}_{4}$ powders. The post-treated powders with spherical shapes converted into nanosized powders. Irrespective of the post-treatment temperatures, the post-treated $\mathrm{NiFe}_{2} \mathrm{O}_{4}$ powders had nanometer sizes.

Figure 6 shows XRD patterns of the post-treated $\mathrm{NiFe}_{2} \mathrm{O}_{4}$ powders. The powders post-treated at a temperature of $600^{\circ} \mathrm{C}$ had a small impurity peak attributed to $\mathrm{Fe}_{2} \mathrm{O}_{3}$. However, phasepure $\mathrm{NiFe}_{2} \mathrm{O}_{4}$ powders were obtained at post-treatment temperatures between 700 and $1000^{\circ} \mathrm{C}$. The mean crystallite sizes of the $\mathrm{NiFe}_{2} \mathrm{O}_{4}$ powders calculated from the peak width of the XRD patterns by Scherrer's equation increased from 29 to $45 \mathrm{~nm}$ when the post-treatment temperature was changed from 600 to $1000^{\circ} \mathrm{C}$, respectively.

The BET surface areas and mean powder sizes calculated from the BET surface areas are shown in Table 1. The BET surface areas of the $\mathrm{NiFe}_{2} \mathrm{O}_{4}$ powders decreased from 23.4 to $11.8 \mathrm{~m}^{2} / \mathrm{g}$ when the post-treatment temperatures were increased from 700 to $1000^{\circ} \mathrm{C}$. Therefore, the average particle sizes of the powders increased from 47.8 to $94.7 \mathrm{~nm}$ when the post-treatment temperatures were increased from 700 to $1000^{\circ} \mathrm{C}$, respectively.

Hysteresis loops of all samples were measured at room temperature. Typical loops for $\mathrm{NiFe}_{2} \mathrm{O}_{4}$ powders post-treated at different temperatures are shown in Fig. 7. The saturation magnetizations and coercivities of the powders post-treated at temperatures between 600 and $1000^{\circ} \mathrm{C}$ are given in Table 1 . The post-treated powders show smooth hysteresis loops, which confirm the formation of pure nickel ferrite. The saturation magnetizations of the $\mathrm{NiFe}_{2} \mathrm{O}_{4}$ powders changed from 32 to 44 emu/g according to changes in the post-treatment temperatures. The increase in the powder size caused an increase in the saturation magnetization; this behavior is in good agreement with the result ${ }^{19)}$ obtained by Morrison and Haneda. The coercivities of the powders changed from 110 to 133 Oe when the post-treatment temperatures were changed from 700 to $1000^{\circ} \mathrm{C}$.

\section{Conclusions}

Powders prepared by spray pyrolysis from the spray solution without citric acid had bimodal size distributions with nanometer and micrometer sizes. The post-treated $\mathrm{NiFe}_{2} \mathrm{O}_{4}$ powders obtained from the spray solution with citric acid had nanometer sizes and regular morphology. The mean sizes of the nanosized $\mathrm{NiFe}_{2} \mathrm{O}_{4}$ powders were controlled by changing the post-treatment temperatures. The saturation magnetizations and coercivities of the nanosized powders were affected by the post-treatment temperatures.

\section{References}

1) M. George, A. M. John, S. S. Nair, P. A. Joy and M. R. Anantharaman, J. Magn. Magn. Mater., 302, 190-195 (2006).

2) H. Yang, X. Zhang, W. Ao and G. Qiu, Mater. Res. Bull., 39, 833-837 (2004).

3) C. MirKin, R. Letsinger, R. Music and J. Storhoff, Nature, 382, 607-609 (1996).

4) M. Sugimoto, J. Am. Ceram. Soc., 82, 269-280 (1999).

5) M. A. Willard, L. K. Kurihara, E. E. Carpenter, S. Calvin and V. G. Harris, Int. Mater. Rev., 49, 125-170 (2004).

6) U. Lüders, A. Barthélémy, M. Bibes, K. Bouzehouance, S. fusil, E. Jacquet, J. P. Contour, J. F. BoBo, J. Fontcuberta and A. Fert, Adv. Mater., 18, 1733-1736 (2006).

7) N.-S. Chen, X. J. Yang, E. S. Liu and J. L. Juang, Sens. 
Actuators B, 66, 178-180 (2000).

8) M. A. A. Elmasry, A. Gaber and E. M. H. Khater, Powder Technol., 90, 161-164 (1997).

9) J. Liu, H. He, X. Jin, Z. Hao and Z. Ju, Mater. Res. Bull., 36, 2357-2363 (2001).

10) J. M. Yang, W. J. Tsuo and F. S. Yen, J. Solid State Chem., 145, 50-57 (1999).

11) V. K. Sankaranarayanan and C. Sreekumar, Curr. Appl. Phys., 3, 205-208 (2003)

12) S. Prasad and N. S. Gajbhiye, J. Alloy. Compd., 265, 87-92 (1998).

13) Y. Shi, J. Ding, X. Liu and J. Wang, J. Magn. Magn. Mater., 205, 249-254 (1999).
14) T. González-Carreño, M. P. Morales and C. J. Serna, Mater. Lett., 43, 97-101 (2000).

15) Q. Li, C. M. Sorensen, K. J. Klabunde and G. C. Hadjipanayis, Aerosol Sci. Technol., 19, 453-467 (1993).

16) H. F. Yu and A. M. Gadalla, J. Mater. Res., 11, 663-670 (1996).

17) J. R. Sohn, Y. C. Kang and H. D. Park, Jpn. J. Appl. Phys., 41, 3006-3009 (2002).

18) S. Che, O. Sakurai, K. Shinozaki and N. Mizutani, J. Aerosol Sci., 29, 271-278 (1998).

19) A. H. Morrison and K. Haneda, J. Appl. Phys., 52, 2496-2498 (1981). 